\title{
INFLUENCE DU TAUX PROTÉIQUE DU RÉGIME SUR LE BILAN AZOTÉ DE LA POULE PONDEUSE
}

\author{
C. CALEI \\ Station de Recherches avicoles \\ Centre national de Recherches zootechniques, Jouy-en-Josas.
}

\section{SOMMAIRE}

Dans les limites étudiées, le taux protéique, du régime de la poule ne retentit pas sur l'intensité de la ponte. Il n'influence nullement le sens du bilan azoté qui demeure constamment positif.

'THORNTON et al. I957, d'une part, et Johnson et Fisher, I959, de 1'autre, ont montré que 1'on peut abaisser le taux protéique du régime de la poule pondeuse dans de larges limites sans observer de diminution de l'intensité de ponte. Il convient toutefois de respecter les besoins minima en acides aminés de la pondeuse. Le but de cette étude est de vérifier ces résultats et de rechercher les variations du bilan azoté de 1'animal lorsque le taux protéique du régime passe de I6 à I2 p. Ioo.

Trente six poules en ponte âgées de 8 mois sont choisies dans un troupeau de Rhode $\mathrm{x}$ Wyandotte selon leur aptitude à la ponte. On rassemble dans trois groupes différents les bonnes, les moyennes et les mauvaises pondeuses. Chaque animal est placé dans une cage individuelle à bilan pendant une période d'adaptation de I mois. Un régime complet et équilibré dosant I6 p. Ioo de matières azotées totales est alors distribué ad libitum. Par la suite chaque groupe est séparé en 2 lots. Le premier continue à recevoir le régime à $\mathrm{I} 6 \mathrm{p}$. Ioo de protéines alors que le second reçoit une ration de I2 p. Ioo de protéines. Cette dernière est obtenue en diluant le régime initial avec de 1'amidon afin de conserver le même équilibre des protéines et des acides aminés. Pendant 5 semaines l'eau et la nourriture sont distribuées à volonté. Le contrôle des ingérés, les récoltes des cufs et des fécès sont effectués quotidiennement. Les récoltes sont rassemblées séparément pour des périodes de 4 jours. Après broyage et homogénéisation, une partie aliquote est prélevée en vue du dosage de l'azote total.

Nous avons mesuré l'intensité de ponte, les quantités d'azote excrétées à la fois sous forme de déjection et sous forme d'œufs. Dans nos résultats ces quantités sont exprimées en pourcentage de l'azote ingéré. La différence à roo exprime la part de cet azote que l'on retrouve dans les tissus. 
'TABLEAU

Bilan azoté de la pondeuse exprimé en pourcentage de l'azote ingéré.

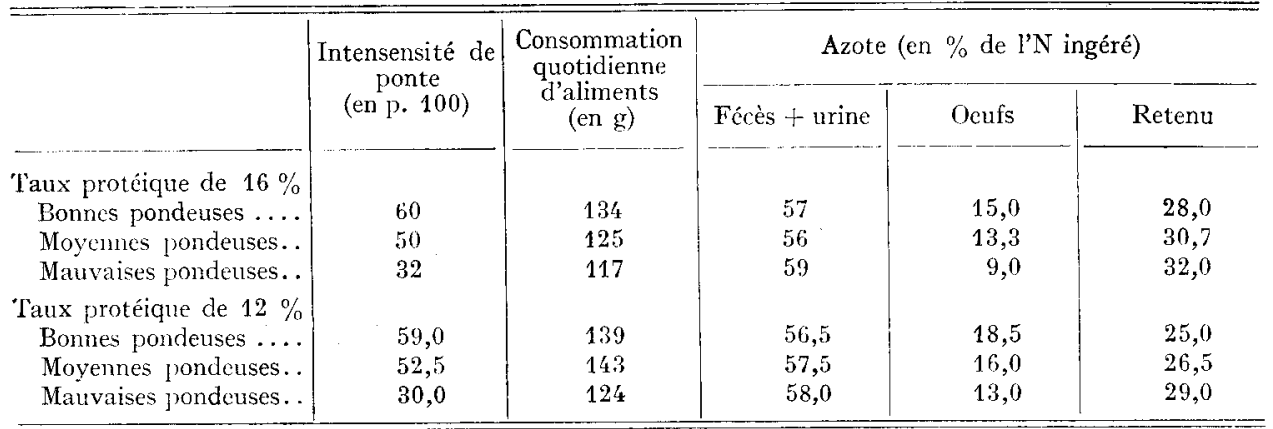

Chez des femelles ayant les mêmes aptitudes à la ponte, le taux protéique du régime n'influence ni le nombre d'œufs pondus ni la consommation d'aliment. Il en résulte que dans les limites observées le niveau alimentaire azoté ne conditionne pas la production des cufs. Nos résultats viennent donc confirmer les conclusions précédemment établies. Par ailleurs, la quantité d'azote excrétée est rigoureusement proportionnelle à la quantité d'azote ingéré quels que soient le taux protéique et l'intensité de ponte. Enfin le résultat le plus spectaculaire concerne le rétention considérable d'azote par la poule. Ce résultat a déjà été signalé par Srorz et ZELENYJ, I953, qui observent une rétention azotée moyenne de 24 p. Ioo de l'azote ingéré chez des poules qui reçoivent un régime titrant 16 p. Ioo de protéines. Nos données ne font pas apparaître de variations dans le pourcentage de l'azote retenu sous l'effet du taux protéique dı régime. On enregistre setılement une faible augmentation du poids corporel.

Reçu en avril 1960.

\section{SUMMARY}

NITROGEN BALANCE OF IAYING HENS.

Nitrogen balance compared to the protein level of the diet was studied in 36 Rhode $\times$ Wyan. dotte laying hens.

In all cases, the balance was positive, whatever the production of the laying hens.

In all animals, the amount of nitrogen uptake represents $25 \mathrm{p}$. I.00 of the nitrogen intake.

\section{RÉFÉRENCES BIBLIOGRAPHIQUES}

Johnson D. Jr., Frsher H., 1959. The amino acid requirement of laying hens. 4. - Supplying minimal levels of essential amino acid from natural feed ingredients. Poult. Sci., 38, I49- 52 .

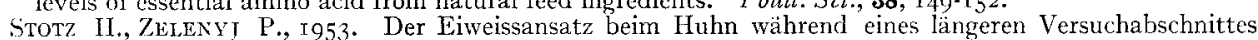
und vergleichend hierzu bei mehrmaliger zehntägiger Unterteilung. Arch. Geflügelk., 16, 54-68.

'Thorntos P. A., Biaylock L. G., Moreng R. F., 1957. Protein level as a factor in egg production. Poull. Sci, 36, 552-557. 